\title{
Borderline pulmonary arterial pressure in systemic sclerosis patients: a post-hoc analysis of the DETECT study
}

Scott H Visovatti ${ }^{1}$, Oliver Distler ${ }^{2}$, J Gerry Coghlan ${ }^{3}$, Christopher P Denton ${ }^{4}$, Ekkehard Grünig ${ }^{5}$, Diana Bonderman ${ }^{6}$, Ulf Müller-Ladner ${ }^{7}$, Janet E Pope ${ }^{8}$, Madelon C Vonk ${ }^{9}$, James R Seibold ${ }^{10}$, Juan-Vicente Torres-Martin ${ }^{11}$, Martin Doelberg ${ }^{11}$, Harbajan Chadha-Boreham ${ }^{11}$, Daniel M Rosenberg ${ }^{11}$, Vallerie V McLaughlin ${ }^{1}$ and Dinesh Khanna ${ }^{12,13^{*}}$

\begin{abstract}
Introduction: Patients with mean pulmonary artery pressures (mPAP) of 21 to $24 \mathrm{~mm} \mathrm{Hg}$ have a so-called borderline elevation of mPAP (BoPAP) - a condition thought to represent early-stage pulmonary arterial vasculopathy. Based on the DETECT study, this post-hoc analysis examined patient characteristics of systemic sclerosis (SSc) patients with normal mPAP, BoPAP and elevated mPAP, fulfilling pulmonary arterial hypertension (PAH) criteria.

Methods: Adult patients with a duration of SSC more than 3 years, a diffusing capacity of the lung for carbon monoxide less than $60 \%$ predicted, and no previous diagnosis of any form of pulmonary hypertension $(\mathrm{PH})$ underwent screening tests followed by right heart catheterization. Subjects were divided into three groups: normal mPAP, BoPAP, and PAH. Exploratory comparative and binary logistic regression analyses were performed for the BoPAP versus normal mPAP and PAH versus BoPAP groups.
\end{abstract}

Results: Of 244 patients evaluated, 148 (60\%) had normal mPAP, 36 (15\%) had BoPAP, and 60 (25\%) had definite PAH. Univariable logistic regression (ULR) showed the mean tricuspid regurgitation velocity in patients with BoPAP to be intermediate between normal mPAP and PAH. In the ULR analyses BoPAP versus normal mPAP and PAH versus BoPAP, the statistically significant predictors were, amongst others: demographic, clinical, pulmonary function, echocardiographic and hemodynamic variables.

Conclusions: In this exploratory post-hoc analysis of the DETECT study population patients with BoPAP could be distinguished from patients with normal mPAP and PAH, and it appears that BoPAP may be an intermediate stage on the continuum between normal PA pressures and PAH.

\section{Introduction}

Systemic sclerosis (SSc, scleroderma) is an autoimmune connective tissue disorder characterized by inflammation, fibrosis and vasculopathy. Pulmonary arterial hypertension $(\mathrm{PAH})$ is a leading cause of death in SSc [1,2]. Based on registry data, modern treatment has improved two-year survival estimates of SSc-associated PAH (SSc-PAH) from

\footnotetext{
* Correspondence: khannad@med.umich.edu

${ }^{12}$ Division of Rheumatology, Department of Internal Medicine, University of Michigan, Ann Arbor, Michigan, USA

${ }^{13}$ Division of Rheumatology, Department of Internal Medicine, University of Michigan Scleroderma Program, 300 North Ingalls Street, Suite 7C27, Ann Arbor, Ml 48109, USA

Full list of author information is available at the end of the article
}

$40 \%$ [3] to 58\% [4], a clear improvement which, however, lags gains seen in other forms of PAH [5-7]. Screening for SSc-PAH is capable of identifying earlier stages of the disease, resulting in earlier intervention that may improve survival [8]. Thus, early diagnosis and treatment of SScPAH is of paramount importance $[9,10]$.

The DETECT study was a multi-center study that systematically evaluated 466 SSc patients at increased risk for development of SSc-PAH [11]. DETECT was the first SScPAH detection study to evaluate all subjects with right heart catheterization (RHC), the gold standard test for the diagnosis of PAH [9]. Detailed demographic, clinical, 
echocardiographic, serologic and functional testing data were also collected.

Measurements in healthy individuals show a normal mean pulmonary arterial pressure (mPAP) to be $14 \pm$ $3.3 \mathrm{mmHg}$ [12], with $2 \mathrm{SD}$ extending the normal range up to $20.6 \mathrm{~mm} \mathrm{Hg}$. The consensus definition of PAH requires $\mathrm{mPAP} \geq 25 \mathrm{mmHg}$ and pulmonary artery wedge pressure (PAWP) of $\leq 15 \mathrm{mmHg}[9,13]$. Thus, a borderline range of mPAPs exists between 21 and $24 \mathrm{~mm} \mathrm{Hg}$ that may represent an early, milder stage of pulmonary vasculopathy in those at high risk of developing PAH [13-15]. This concept is especially relevant in connective tissue diseases (CTD), such as SSc, where progressive vasculopathy is highly prevalent and may be an important distinction from idiopathic PAH [13]. The objective of this post-hoc analysis was to compare the demographics and clinical features of patients with normal PAP, borderline mPAP (BoPAP), and elevated PAP (PAH) in a large international cohort of patients with SSc who participated in the DETECT study. The identification of characteristics specific to SSc patients with BoPAP would facilitate future investigations into the natural history of this condition, and provide insights into the proportion of patients who develop PAH.

\section{Methods}

\section{Study design}

Our study was conducted in accordance with the Declaration of Helsinki and its amendments, followed the International Conference on Harmonization Guideline for Good Clinical Practice, and was approved by local institutional review boards/ethics committees (a complete list is included as Additional file 1). RHC and echocardiography protocols were standardized and conducted systematically, and serum laboratory testing as well as data management were performed centrally. Data quality was monitored rigorously. All patients provided written informed consent. Patients were eligible for inclusion in DETECT if they were aged $\geq 18$ years and had: 1 ) a definite diagnosis of SSc [16] of $>3$ years' duration from first non-Raynaud's symptom; 2) a diffusing capacity of the lung for carbon monoxide (DLCO) $<60 \%$ of predicted; 3) a forced vital capacity (FVC) $\geq 40 \%$ of predicted; and 4) not had pulmonary hypertension confirmed by RHC prior to enrolment.

\section{Current analysis population}

Patients were included in the current analysis if they had: 1) a pulmonary artery wedge pressure (PAWP) $\leq 15 \mathrm{mmHg}$ by RHC; 2) no significant interstitial lung disease (ILD; defined as FVC $<60 \%$ or FVC between 60 and $70 \%$ with moderate-to-severe fibrosis on high resolution computed tomography); 3) no systemic hypertension (stage-I hypertension defined as systolic blood pressure $\geq 140 \mathrm{mmHg}$ or diastolic blood pressure $\geq 90$ ) [17]; and 4) no left atrial enlargement (defined as $3.9 \mathrm{~cm}$ for women and $4.1 \mathrm{~cm}$ for men) [18]. DETECT screened 646 SSc patients, and enrolled 488 SSc patients with 466 who underwent RHC. A total of 222 of 466 were excluded from the present analysis due to: 1) a pulmonary artery wedge pressure (PAWP) $>15 \mathrm{mmHg}$ or significant ILD (138 patients), and 2) an enlarged left atrium or stage-I or greater hypertension (84 patients). Eligible patients comprise the PAP analysis set and were categorized into three PAP groups for analysis, based on the mPAP by RHC: 1) normal mPAP (<21 mmHg); 2) BoPAP (mPAP 21 to $24 \mathrm{mmHg}$ ); and 3) PAH (mPAP $\geq 25 \mathrm{mmHg}$ ). Analysis of variables was performed using these three PAP groups.

\section{Data collection and analysis}

The DETECT study collected 112 variables, collated into four groups: 1) demographic and clinical parameters (68 variables); 2) serum tests (13 variables); 3) electrocardiography (ECG) (3 variables); and 4) echocardiography (28 variables). In the present study, variables were selected for further analysis based on a review of numerical descriptive differences between the three groups, as well as input from the authors on feasibility of the variables and their clinical relevance to PAH. Two additional variables were computed: 1 ) the transpulmonary gradient (TPG) which is the difference between mPAP and left atrial pressure (estimated by the PAWP); and 2) the diastolic wedge gradient (DWG) which is the difference between diastolic PAP and left atrial pressure (estimated by the PAWP). The selected variables were described using summary statistics: sample size, mean, SD, median, upper and lower quartiles, minimum and maximum for quantitative data and frequencies (counts and percentages) for qualitative and categorical data. The distributions of the variables were compared using non-parametric tests: Wilcoxon rank-sum and chi-square/Fisher's exact test for continuous and categorical data, respectively. Univariable logistic regression (ULR) analysis was performed using BoPAP versus normal mPAP and PAH versus BoPAP as binary outcomes in separate models. The odds ratio (OR) and 95\% CI for each variable was calculated and statistical significance was examined by the Wald chi-square test. A Forest plot was constructed to display the odds ratios and the $95 \%$ CI for 13 variables in the BoPAP versus normal $\mathrm{mPAP}$ and $\mathrm{PAH}$ versus BoPAP groups. Variables were selected for the plot if they met the statistical significance criteria or had potential clinical utility as screening tests for BoPAP and PAH. RHC hemodynamics were used for exploratory purposes only, as they were part of the group definitions.

\section{Results}

Among the 244 SSc patients included in the PAP analysis set, $60 \%(\mathrm{n}=148)$ had a normal mPAP, 15\% $(\mathrm{n}=36)$ had BoPAP and 25\% $(n=60)$ had an elevated mPAP (PAH) (Figure 1). 


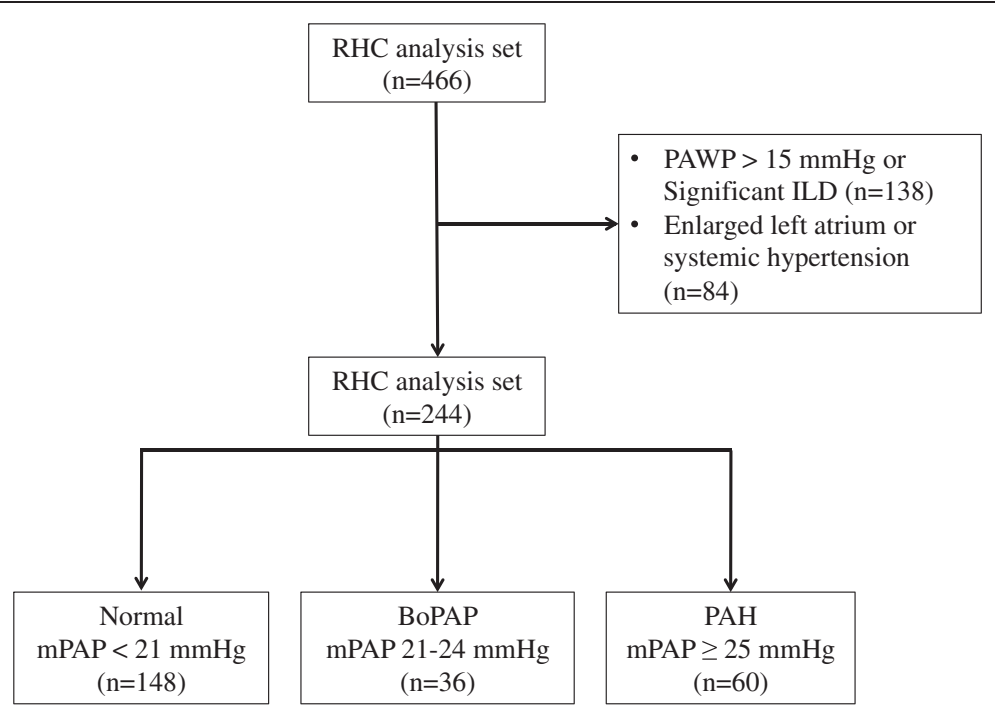

Figure 1 Patient disposition. This study focuses on the differences between the normal mean pulmonary arterial pressure (mPAP), borderline pulmonary arterial pressure (BOPAP) and pulmonary arterial hypertension (PAH) subgroups of the DETECT study. ILD, interstitial lung disease; PAWP, pulmonary artery wedge pressure; RHC, right heart catheterization.

\section{Baseline characteristics of patients with normal mPAP, BoPAP and PAH}

Statistically significant differences between the BoPAP and other groups were found in clinical, serologic, echocardiographic, and invasive hemodynamic parameters, including World Health Organization functional class (WHO FC) (PAH versus BoPAP), presence of peripheral edema (BoPAP versus normal mPAP), presence of telangiectasias (PAH versus BoPAP), ratio of FVC percent predicted/DLCO percent predicted (PAH versus BoPAP), TLC percent predicted (BoPAP versus normal mPAP), presence of anti-centromere antibodies (PAH versus BoPAP), $\log _{10}$ NT-proBNP (BoPAP versus normal mPAP), serum urate (PAH versus BoPAP), left atrium diameter (BoPAP versus normal mPAP, tricuspid annular plane systolic excursion (TAPSE, PAH versus BoPAP) and TR velocity (BoPAP versus both normal PAP and PAH; Table 1). Differences in the exploratory comparison of hemodynamic variables (PAWP, TPG, DWG and pulmonary vascular resistance (PVR)) were also noted.

\section{Univariable logistic regression analysis BoPAP versus normal PAP}

As shown in Table 2 and Figure 2, ULR models of SSc patients with BoPAP versus normal mPAP identified the following variables as being statistically significant predictors of BoPAP $(P<0.05)$ : older age, presence of peripheral edema, a higher $\log _{10} \mathrm{NT}$-proBNP, greater left atrium diameter, and greater tricuspid regurgitation (TR) velocity. Of note, 6-minute walk distance was not statistically different.
The RHC variables PAWP, TPG and PVR (which defined the groups) were all statistically significant, though DWG was not.

\section{PAH versus BoPAP}

ULR models of SSc patients with PAH versus BoPAP identified the following variables as being statistically significant $(P<0.05)$ predictors of PAH: higher WHO FC (III or IV), diffuse versus limited disease subtype, the presence of telangiectasias, higher FVC percent predicted/DLCO percent predicted ratio, presence of anti-centromere antibodies, higher serum urate, a lower TAPSE and a higher TR velocity. As was the case with the BoPAP versus normal PAP analysis, 6-minute walk distance was not statistically different. As expected, the PAH group had a higher TPG, a higher DWG, and a higher PVR (Table 2 and Figure 2). Of note, the PAWP was not significantly different between these groups.

\section{Discussion}

Expert consensus opinion from the recent 5th World Symposium on Pulmonary Hypertension acknowledges that a borderline mPAP between 21 and $24 \mathrm{mmHg}$ in SSc patients is associated with 'a high risk of future development of manifest $\mathrm{PAH}$ ', and recommends careful follow up of these patients [13]. In our current study of a large, well-defined, high-risk SSc cohort we identified clinical and laboratory features that differentiate the BoPAP group from groups with normal mPAP and PAH. Our study provides a crucial first step towards the development of future longitudinal studies of BoPAP, as we 
Table 1 Baseline characteristics of patients with normal mPAP, BoPAP and PAH

\begin{tabular}{|c|c|c|c|c|c|}
\hline \multirow[b]{2}{*}{ Variable } & \multicolumn{3}{|c|}{ Patient groups $(\mathrm{N}=244)$} & \multicolumn{2}{|l|}{$P$-value } \\
\hline & $\begin{array}{l}\text { Normal mPAP } \\
(\mathrm{N}=148)\end{array}$ & $\begin{array}{l}\text { BoPAP } \\
(N=36)\end{array}$ & $\begin{array}{l}\text { PAH } \\
(\mathrm{N}=60)\end{array}$ & $\begin{array}{l}\text { BoPAP versus } \\
\text { normal mPAP }\end{array}$ & $\begin{array}{l}\text { PAH versus } \\
\text { BoPAP }\end{array}$ \\
\hline \multicolumn{6}{|l|}{ Demographic and clinical parameters } \\
\hline Age, years, $\mathrm{N}^{\mathrm{a}}$ & 148 & 36 & 59 & & \\
\hline Mean \pm SD & $54.3 \pm 12.0$ & $58.4 \pm 9.5$ & $61.6 \pm 9.7$ & & \\
\hline Median, Q1 to Q3 & $55.0,46.0$ to 63.5 & $58.5,52.5$ to 63.5 & $62.0,56.0$ to 68.0 & & \\
\hline Minimum, maximum & $26.0,78.0$ & $43.0,80.0$ & $33.0,80.0$ & & \\
\hline Gender, $\mathrm{n}$ & 148 & 36 & 60 & & \\
\hline Male, n (\%) & $18(12.2)$ & $6(16.7)$ & $12(20.0)$ & & \\
\hline Female, n (\%) & $130(87.8)$ & $30(83.3)$ & $48(80.0)$ & & \\
\hline WHO FC, N & 139 & 34 & 60 & & $<0.05$ \\
\hline I/II, n (\%) & $127(91.4)$ & $28(82.4)$ & $37(61.7)$ & & \\
\hline III/IV, n (\%) & $12(8.6)$ & $6(17.6)$ & $23(38.3)$ & & \\
\hline 6-minute walk distance, $\mathrm{N}$ & 108 & 27 & 48 & & \\
\hline Mean \pm SD & $422.4 \pm 110.4$ & $397.4 \pm 102.3$ & $391.4 \pm 109.8$ & & \\
\hline Median, Q1 to Q3 & $432.5,364.5$ to 502.0 & $414.5,341.0$ to 472.0 & $395.0,318.0$ to 460.5 & & \\
\hline SSC disease duration (years), $\mathrm{N}$ & 147 & 36 & 60 & & \\
\hline Mean \pm SD & $11.0 \pm 8.0$ & $10.0 \pm 5.0$ & $14.0 \pm 12.0$ & & \\
\hline Median, Q1 to Q3 & $8.0,5.0$ to 13.0 & $9.0,6.0$ to 15.0 & $11.0,6.0$ to 16.0 & & \\
\hline SSc subtype, N & 146 & 36 & 59 & & \\
\hline Limited, n (\%) & $90(61.6)$ & $20(55.6)$ & $44(74.6)$ & & \\
\hline Diffuse, n (\%) & $45(30.8)$ & $13(36.1)$ & $10(16.9)$ & & \\
\hline Overlap/mixed CTD, n (\%) & $11(7.5)$ & $3(8.3)$ & $5(8.5)$ & & \\
\hline Presence of peripheral edema, n/N (\%) & 8/147 (5.4) & $7 / 36(19.4)$ & $11 / 60(18.3)$ & $<0.01$ & \\
\hline Presence of telangiectasias, n/N (\%) & 108/148 (73.0) & $22 / 36(61.1)$ & $52 / 60(86.7)$ & & $<0.005$ \\
\hline FVC \% predicted, $\mathrm{N}$ & 148 & 36 & 60 & & \\
\hline Mean \pm SD & $92.5 \pm 17.6$ & $88.7 \pm 14.5$ & $92.0 \pm 19.7$ & & \\
\hline Median, Q1-Q3 & $91.9,79.9$ to 102.7 & $87.1,80.0$ to 96.5 & $89.5,77.2$ to 102.5 & & \\
\hline FVC \% predicted /DLCO \% predicted, N & 148 & 36 & 60 & & $<0.01$ \\
\hline Mean \pm SD & $1.9 \pm 0.4$ & $1.9 \pm 0.4$ & $2.3 \pm 0.7$ & & \\
\hline Median, Q1 to Q3 & $1.8,1.5$ to 2.1 & $2.0,1.5$ to 2.2 & $2.2,1.8$ to 2.5 & & \\
\hline TLC \% predicted, N & 127 & 28 & 54 & $<0.05$ & \\
\hline Mean \pm SD & $92.8 \pm 21.9$ & $84.8 \pm 14.4$ & $88.1 \pm 21.6$ & & \\
\hline Median, Q1 to Q3 & $92.5,80.0$ to 106.0 & $83.0,74.0$ to 95.0 & $87.3,78.0$ to 100.3 & & \\
\hline \multicolumn{6}{|l|}{ Serum laboratory tests } \\
\hline Presence of anti-centromere antibodies & & & & & $<0.05$ \\
\hline $\mathrm{n} / \mathrm{N}(\%)$ & 49/141 (34.8) & $10 / 34(29.4)$ & $30 / 56(53.6)$ & & \\
\hline $\log _{10}$ NT-proBNP (pg/ml), N & 141 & 34 & 56 & $<0.05$ & \\
\hline Mean \pm SD & $2.0 \pm 0.5$ & $2.2 \pm 0.5$ & $2.4 \pm 0.5$ & & \\
\hline Median, Q1 to Q3 & $2.1,1.7$ to 2.3 & $2.2,1.9$ to 2.5 & $2.3,2.0$ to 2.8 & & \\
\hline Serum urate, $\mathrm{mg} / 100 \mathrm{ml}, \mathrm{N}$ & 141 & 34 & 56 & & $<0.01$ \\
\hline Mean \pm SD & $4.7 \pm 1.4$ & $4.7 \pm 1.3$ & $5.6 \pm 1.4$ & & \\
\hline Median, Q1 to Q3 & $4.4,3.7$ to 5.3 & $4.5,3.7$ to 5.4 & $5.6,4.6$ to 6.5 & & \\
\hline
\end{tabular}


Table 1 Baseline characteristics of patients with normal mPAP, BoPAP and PAH (Continued)

\begin{tabular}{|c|c|c|c|c|c|}
\hline \multirow[t]{3}{*}{$\log _{10}$ estimated GFR } & 141 & 34 & 55 & & \\
\hline & $1.9 \pm 0.1$ & $1.9 \pm 0.1$ & $1.9 \pm 0.1$ & & \\
\hline & $1.9,1.9$ to 2.0 & $1.9,1.8$ to 2.0 & $1.9,1.8$ to 2.0 & & \\
\hline \multicolumn{6}{|l|}{ Echocardiography } \\
\hline Left atrium diameter, $\mathrm{mm}, \mathrm{N}$ & 148 & 36 & 60 & $<0.001$ & \\
\hline Mean \pm SD & $30.2 \pm 5.1$ & $33.9 \pm 3.6$ & $31.8 \pm 5.4$ & & \\
\hline Median, Q1 to Q3 & $31.0,27.8$ to 34.0 & $33.5,31.0$ to 37.0 & $32.0,30.0$ to 36.0 & & \\
\hline Right atrium area, $\mathrm{cm}^{2}, \mathrm{~N}$ & 142 & 33 & 58 & & $<0.05$ \\
\hline Mean \pm SD & $12.8 \pm 4.7$ & $14.7 \pm 5.9$ & $16.8 \pm 5.8$ & & \\
\hline Median, Q1 to Q3 & $12.0,10.0$ to 14.3 & $12.4,10.5$ to 18.0 & $15.8,13.4$ to 20.0 & & \\
\hline TAPSE (mm), N & 138 & 33 & 53 & & \\
\hline Mean \pm SD & $23.2 \pm 4.3$ & $23.8 \pm 5.1$ & $21.1 \pm 4.3$ & & \\
\hline Median, Q1 to Q3 & $23.7,20.4$ to 26.0 & $23.0,20.0$ to 27.0 & $20.8,19.0$ to 23.0 & & \\
\hline TR velocity $(\mathrm{m} / \mathrm{s}), \mathrm{N}$ & 140 & 35 & 58 & $<0.001$ & $<0.05$ \\
\hline Mean \pm SD & $2.3 \pm 0.4$ & $2.7 \pm 0.3$ & $3.0 \pm 0.7$ & & \\
\hline Median, Q1 to Q3 & $2.3,2.2$ to 2.6 & $2.7,2.5$ to 2.9 & $2.9,2.5$ to 3.5 & & \\
\hline \multicolumn{6}{|l|}{ Electrocardiography } \\
\hline Presence of right axis deviation, n/N (\%) & 2/138 (1.4) & $1 / 30(3.3)$ & $8 / 58(13.8)$ & & \\
\hline \multicolumn{6}{|l|}{ Right heart catheterization } \\
\hline PAWP, mmHg, N & 148 & 36 & 60 & $<0.001$ & \\
\hline Mean \pm SD & $7.7 \pm 3.3$ & $10.8 \pm 3.0$ & $9.9 \pm 3.3$ & & \\
\hline Median, Q1 to Q3 & $8.0,5.0$ to 10.0 & $11.0,9.0$ to 13.0 & $10.5,7.5$ to 12.5 & & \\
\hline TPG, mmHg, N & 148 & 36 & 60 & $<0.001$ & $<0.001$ \\
\hline Mean \pm SD & $7.9 \pm 2.7$ & $11.6 \pm 2.8$ & $22.3 \pm 9.7$ & & \\
\hline Median, Q1 to Q3 & $7.0,6.0$ to 10.0 & $11.0,10.0$ to 13.0 & $20.0,15.0$ to 28.0 & & \\
\hline DWG, mmHg, N & 148 & 36 & 60 & & $<0.001$ \\
\hline Mean \pm SD & $1.8 \pm 2.7$ & $3.0 \pm 5.4$ & $10.7 \pm 8.1$ & & \\
\hline Median, Q1 to Q3 & $1.0,0.0$ to 3.0 & $2.0,0.5$ to 5.0 & $8.0,5.0$ to 17.0 & & \\
\hline PVR, dyn.sec/cm ${ }^{5}, \mathrm{~N}$ & 148 & 36 & 60 & $<0.001$ & $<0.001$ \\
\hline Mean \pm SD & $128.0 \pm 50.8$ & $179.8 \pm 58.7$ & $375.8 \pm 217.0$ & & \\
\hline Median, Q1 to Q3 & $121.5,91.3$ to 153.9 & $170.3,147.8$ to 187.8 & $295.5,236.0$ to 419.1 & & \\
\hline
\end{tabular}

${ }^{a} \mathrm{~N}$ for each variable represents the number of patients with available data. Statistical tests were Wilcoxon rank-sum for continuous data and chi-square/Fisher's exact for categorical data. These variables were analysed for completeness, but it should be borne in mind that they are part of the definition of the analysis groups. BoPAP, borderline pulmonary arterial pressure; CTD, connective tissue disease; DLCO, diffusing capacity of carbon monoxide; DWG, diastolic wedge gradient; FVC, forced vital capacity; GFR, glomerular filtration rate; NT-proBNP, N-terminal pro-brain natriuretic peptide; PAH, pulmonary arterial hypertension; PAWP, pulmonary artery wedge pressure; PVR, pulmonary vascular resistance; Q, quartile; SSC, systemic sclerosis; TAPSE, tricuspid annular plane systolic excursion; TLC, total lung capacity; TPG, transpulmonary gradient; TR, tricuspid regurgitation; WHO FC, World Health Organization functional class.

provide a panel of variables that can be tested to determine their prognostic utility.

Formalized early detection of SSc-PAH has been shown to identify milder forms of the disease, resulting in opportunities for earlier management $[8,19]$. As algorithms and practice guidelines are developed to improve early detection of SSc-PAH, it is likely that referrals for RHC will increase (in DETECT the rate increased from $40 \%$ to $62 \%$ ). The increase in RHCs will likely result in more patients identified with both PAH and BoPAP. The finding of
BoPAP is significant, as a number of recent studies have shown an association between BoPAP and worse clinical outcomes [14,15,20]. Thus, further characterization of BoPAP is important. In the current study we identify significant differences in clinical, serologic, echocardiographic and hemodynamic parameters useful in differentiating BoPAP from normal PAP and PAH from BoPAP groups.

A number of recent studies have shown an association between BoPAP and worse clinical outcomes. One small study compared SSc patients with mPAPs $>17$ 
Table 2 Univariable logistic regression analysis of patients with BoPAP versus normal PAP and those with PAH versus BoPAP

\begin{tabular}{|c|c|c|c|c|}
\hline \multirow[t]{2}{*}{ Variable } & \multicolumn{2}{|c|}{ Odds ratios ( $95 \%$ confidence interval) } & \multicolumn{2}{|l|}{$P$-value } \\
\hline & BoPAP versus normal mPAP & PAH versus BoPAP & BoPAP versus normal mPAP & PAH versus BoPAP \\
\hline \multicolumn{5}{|l|}{ Demographic and clinical parameters } \\
\hline Age, years & $1.03(1.00,1.07)$ & $1.04(0.99,1.08)$ & & \\
\hline Gender, female versus male & $0.69(0.25,1.89)$ & $0.80(0.27,2.36)$ & & \\
\hline WHO FC, III/IV versus I/II & $2.27(0.78,6.56)$ & $2.90(1.04,8.08)$ & & $<0.05$ \\
\hline 6-minute walk distance & $1.00(0.99,1.00)$ & $1.00(1.00,1.00)$ & & \\
\hline SSc disease duration, years & $0.99(0.94,1.04)$ & $1.05(1.00,1.11)$ & & \\
\hline SSC disease subtype & & & & $<0.05$ \\
\hline dcSSc versus IcSSc & $1.30(0.59,2.85)$ & $0.35(0.13,0.93)$ & & \\
\hline Overlap/mixed CTD versus IcSSC & $1.23(0.31,4.81)$ & $0.76(0.17,3.48)$ & & \\
\hline Presence of telangiectasias & $0.58(0.27,1.25)$ & $4.13(1.52,11.26)$ & & $<0.01$ \\
\hline Presence of peripheral edema & $4.19(1.41,12.46)$ & $0.93(0.32,2.67)$ & $<0.05$ & \\
\hline FVC predicted & $0.99(0.97,1.01)$ & $1.01(0.99,1.04)$ & & \\
\hline FVC \% predicted /DLCO \% predicted & $1.24(0.54,2.82)$ & $3.41(1.36,8.54)$ & & $<0.01$ \\
\hline TLC \% predicted & $0.98(0.96,1.00)$ & $1.01(0.99,1.04)$ & & \\
\hline \multicolumn{5}{|l|}{ Serum laboratory } \\
\hline Presence of anti-centromere antibodies & $0.78(0.35,1.77)$ & $2.77(1.12,6.85)$ & & $<0.05$ \\
\hline $\log _{10}$ NT-proBNP, pg/ml & $2.65(1.17,5.98)$ & $1.69(0.71,4.05)$ & $<0.05$ & \\
\hline Serum urate, mg/100 ml & $1.01(0.76,1.33)$ & $1.73(1.20,2.48)$ & & $<0.01$ \\
\hline $\log _{10}$ estimated GFR & $0.54(0.03,9.44)$ & $0.04(0.00,1.77)$ & & \\
\hline \multicolumn{5}{|l|}{ Echocardiography } \\
\hline Left atrium diameter, mm & $1.22(1.10,1.35)$ & $0.89(0.80,1.00)$ & $<0.001$ & $<0.05$ \\
\hline Right atrium area, $\mathrm{cm}^{2}$ & $1.07(1.00,1.14)$ & $1.07(0.99,1.17)$ & & \\
\hline TAPSE, mm & $1.03(0.94,1.12)$ & $0.88(0.80,0.98)$ & & $<0.05$ \\
\hline TR velocity, $\mathrm{m} / \mathrm{s}$ & $25.10(6.07,103.74)$ & $3.15(1.30,7.67)$ & $<0.0001$ & $<0.05$ \\
\hline \multicolumn{5}{|l|}{ Electrocardiography } \\
\hline Right axis deviation & $2.35(0.21,26.74)$ & $4.64(0.55,38.99)$ & & \\
\hline \multicolumn{5}{|l|}{ Right heart catheterization } \\
\hline PAWP, mmHg & $1.39(1.21,1.61)$ & $0.91(0.79,1.04)$ & $<0.0001$ & \\
\hline $\mathrm{TPG}, \mathrm{mmHg}$ & $1.57(1.33,1.85)$ & $1.72(1.35,2.19)$ & $<0.0001$ & $<0.0001$ \\
\hline DWG, mmHg & $1.10(0.99,1.21)$ & $1.27(1.12,1.44)$ & & $<0.0005$ \\
\hline PVR, dyn.sec/ $\mathrm{cm}^{5}$ & $1.01(1.01,1.02)$ & $1.03(1.01,1.04)$ & $<0.0001$ & $<0.0001$ \\
\hline
\end{tabular}

BoPAP, borderline pulmonary arterial pressure; CTD, connective tissue disease; dcSSc, diffuse cutaneous SSc; DLCO, diffusing capacity of carbon monoxide; DWG, diastolic wedge gradient; FVC, forced vital capacity; GFR, glomerular filtration rate; IcSSc, limited cutaneous SSc; NT-proBNP, N-terminal pro-brain natriuretic peptide; PAH, pulmonary arterial hypertension; PAWP, pulmonary artery wedge pressure; PVR, pulmonary vascular resistance; SSc, systemic sclerosis; TAPSE, tricuspid annular plane systolic excursion; TLC, total lung capacity; TPG, transpulmonary gradient; TR, tricuspid regurgitation; WHO FC, World Health Organization functional class.

but $<25 \mathrm{mmHg}$ (group mean of $20 \pm 2 \mathrm{mmHg}$ ) to those with $\mathrm{mPAPs} \leq 17 \mathrm{mmHg}$ (group mean $14 \pm 2 \mathrm{mmHg}$ ), and found the former group to be associated with both shorter mean 6-minute walk distances $(396 \pm 71$ meters versus $488 \pm 77$ meters, $P<0.005)$ and lower mean percent predicted peak oxygen consumption $\left(\mathrm{VO}_{2}\right)$ values $(76 \pm 11 \%$ versus $90 \pm 24 \%, P=0.05$ ) [20]. The PHAROS registry included 206 SSc patients at increased risk for PAH who underwent RHC [21]. After excluding patients with significant interstitial lung disease, a comparison of SSc patients with normal mPAP (group median $16 \mathrm{mmHg}$ ) and borderline mPAP (group median $23 \mathrm{mmHg}$ ) showed the latter group to have significantly higher right ventricular systolic pressures on echocardiogram, higher pulmonary vascular resistance and a higher transpulmonary gradient [14]. Follow-up data involving 24 PHAROS patients who 


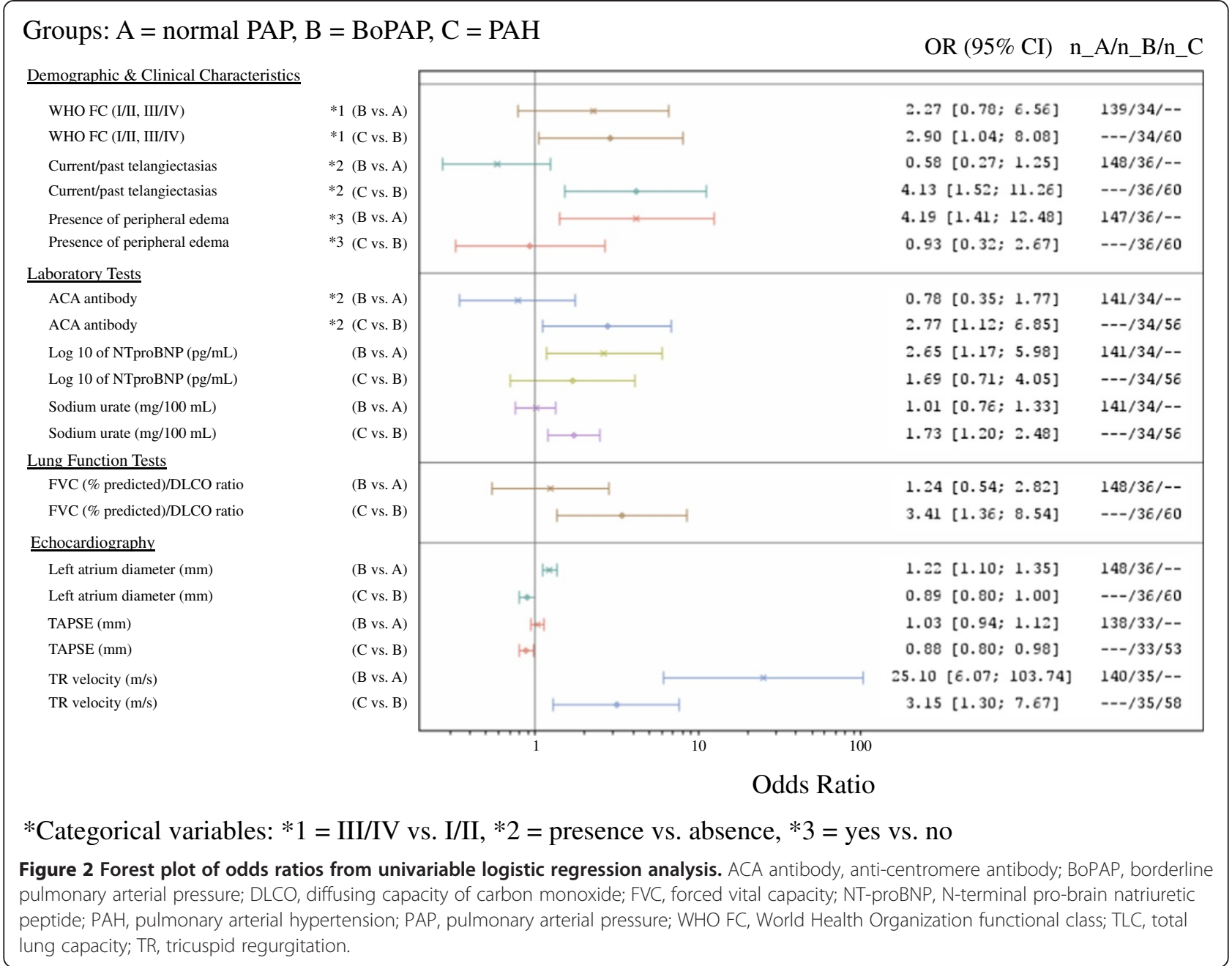

underwent repeat $\mathrm{RHC}$ at a later date showed that $32 \%$ of patients with normal mPAP and $55 \%$ of patients with borderline mPAP developed resting PH ( $P$-value not significant) $14.92 \pm 9.23$ and $12.19 \pm 6.82$ months after the first $\mathrm{RHC}$, respectively [14]. Another analysis compared the outcomes of SSc patients with mPAP $\leq 20 \mathrm{mmHg}$ to those with mPAPs of 21 to $24 \mathrm{mmHg}$ [15]. Within 228 patients without ILD, 142 had normal mPAP and 86 had mPAP of 21 to $24 \mathrm{mmHg}$. Clinically indicated repeat RHCs were performed in 38 patients from each group and the hazard ratio for $\mathrm{PAH}$ diagnosis on the subsequent $\mathrm{RHC}$ for the borderline mPAP group compared to the normal mPAP group was 3.7 (95\% CI 1.7, 8.0, $P<0.001$ ). Within the borderline mPAP group, 18.5\% (95\% CI 8.3, 28.7) developed PAH within 3 years, and 27.1\% (95\% CI 13.9, 40.3) developed PAH within 5 years [15].

In the current study we identified significant differences in clinical, serologic, echocardiographic and hemodynamic parameters useful in differentiating BoPAP from normal PAP and PAH from BoPAP groups. Across both comparisons, TR velocity was the variable most strongly associated with BoPAP (versus normal mPAP) and PAH (versus BoPAP).

Our analysis also identified additional variables capable of differentiating BoPAP from the PAH group: WHO functional class, SSc subtype, presence of telangiectasias, ratio of \% predicted FVC/percent predicted DLCO, anti-centromere antibodies, and serum urate concentration. Some of these variables (telangiectasia [22], FVC/ DLCO [22], anti-centromere antibodies [22-24], and serum urate [25]) have been useful in predicting SSc-PAH in other studies.

Invasive pressure measurements including TPG and DWG were explored, as these measurements have been addressed in other studies of BoPAP. Elevations in these gradients ( $\geq 12 \mathrm{mmHg}$ and $\geq 5$, respectively) [26] are believed consistent with pulmonary vascular disease, and thus, help separate individuals with $\mathrm{PAH}$ from those with pulmonary venous hypertension. As described previously [15], the TPG in our study was capable of separating the 
BoPAP group from the normal PAP and PAH groups. We also show the DWG to be useful in differentiating the BoPAP group from the PAH group, and it has the added benefit of being able to differentiate $\mathrm{PAH}$ from postcapillary $\mathrm{PH}$ [26]. Though not in the abnormal range, the mean TPG and DWG measurements for the BoPAP group were intermediate between the normal PAP and $\mathrm{PAH}$ groups, perhaps suggesting that a subset of SSc patients with BoPAP may have early pulmonary vasculopathy.

In the present study we excluded patients with overt pulmonary venous hypertension based upon the finding of a PAWP $>15 \mathrm{mmHg}$ by RHC. It is important to acknowledge that occult pulmonary venous hypertension $(\mathrm{OPVH})$ due to left heart disease may have been present in a proportion of patients who underwent a RHC while in a state of volume depletion, and were thus found to have underestimated left-heart filling pressures [27]. One study involving patients with scleroderma found that 6 out of 24 patients who originally met the criteria for $\mathrm{PAH}$ by RHC were subsequently diagnosed with $\mathrm{OPVH}$ after a fluid challenge [28]. As a fluid challenge was not included in our RHC study protocol, we minimized the likelihood of including patients with OPVH by excluding individuals with conditions commonly associated with OPVH: stage I or greater systemic hypertension and/or abnormally enlarged left atrium. Future BoPAP studies should consider the use of evocative maneuvers such as fluid challenge or exercise in order to identify patients with OPVH.

Our study has significant strengths. Ours is the first BoPAP study to mandate a diagnostic RHC in all subjects, allowing us to assign individuals into groups (normal mPAP, BoPAP and PAH) based on rigorous, objective criteria. Standardization of the study protocol and centralization of serum laboratory testing and data management assured homogeneity. In addition, it is the largest, most complete cohort of patients evaluated for SSc-PAH, providing us a sufficient sample size to conduct our analyses.

Our study has important limitations. Results are crosssectional, so longitudinal follow up to determine the incidence of PAH in the BoPAP group over time was not determined. Our inclusion criteria included a DLCO $<60 \%$ to enrich for a higher likelihood of PAH. Thus, the groups analyzed in our study represent a high-risk SSc group, and may not be representative of the general SSc population. Future studies are needed in order to expand our findings into the general SSc population. Our study was not designed to compare and model relationships involving the BoPAP sub-group; thus, multivariable logistic regression for this post-hoc sub-analysis could be misleading, and was not performed. In addition, the three sub-groups analyzed (normal mPAP, BoPAP and PAH) were defined using mPAP (a continuous variable). Various pairwise sub- groups using binary logistic regression may provide a different set of predictive covariables for each multiple regression model that may be inaccurate.

\section{Conclusion}

In conclusion, our study identifies clinical, echocardiographic, hemodynamic, pulmonary function, and serologic variables that allow SSc patients with BoPAP to be differentiated from SSc patients with normal mPAPs and PAH. Future longitudinal studies designed to reassess patients with BoPAP at pre-designated time points would be the ideal means of validating the prognostic value of our findings. Such studies would allow further characterization of the natural history of BoPAP, including the rate and frequency of conversion to pre-capillary or post-capillary $\mathrm{PH}$. Our exploratory analyses of hemodynamic data suggest that the TPG and DWG should continue to be evaluated as potential predictors for the development of PAH in the SSc population.

\section{Additional file}

Additional file 1: Institutional ethics committees and review boards.

\section{Abbreviations}

BoPAP: borderline elevation of the mean pulmonary arterial pressure; CTD: connective tissue disease; DLCO: diffusing capacity of the lung for carbon monoxide; DWG: diastolic wedge gradient; FVC: forced vital capacity; GFR: glomerular filtration rate; HFpEF: heart failure with preserved ejection fraction; ILD: interstitial lung disease; $\mathrm{mmHg}$ : millimeters of mercury; mPAP: mean pulmonary arterial pressure; NT-proBNP: N-terminal pro-brain natriuretic hormone; OPVH: occult pulmonary venous hypertension; OR: odds ratio; PAH: pulmonary arterial hypertension; PAWP: pulmonary artery wedge pressure; PVR: pulmonary vascular resistance; RHC: right heart catheterization; ROC AUC: receiver operating characteristic area under the curve;

SSc: systemic sclerosis (scleroderma); SSC-PAH: scleroderma-associated pulmonary arterial hypertension; TAPSE: tricuspid annular plane systolic excursion; TLC: total lung capacity; TPG: transpulmonary gradient; TR: tricuspid regurgitation; ULR: univariable logistic regression; $\mathrm{VO}_{2}$ : oxygen consumption; WHO FC: World Health Organization functional class.

\section{Competing interests}

OD has/had consultancy relationship and/or has received research funding in the area of systemic sclerosis and related conditions from Actelion, Pfizer, Ergonex, BMS, Sanofi-Aventis, United BioSource Corporation, Roche/Genentech, Medac, Biovitrium, Boehringer Ingelheim Pharma, Novartis, 4 D Science, Active Biotec, Bayer-Schering, Sinoxa, Serodapharm, EpiPharm, Biogen and GSK. JGC has consultancy relationships, received lecture honoraria and/or has received research funding from Actelion Pharmaceuticals Ltd, Pfizer, GlaxoSmithKline and United Therapeutics. CPD has received research funding or had consultancy relationship with Actelion, GSK, Pfizer, Sanofi-Aventis, Roche, Novartis and Merck-Serono. EG has received honoraria for consultations and/or speaking at conferences from Actelion Pharmaceuticals Ltd, Bayer, Gilead, GlaxoSmithKline, Lilly, Milteney, Novartis, Pfizer and Rotex Medica, and funding for clinical trials from Actelion Pharmaceuticals Ltd, Bayer, GlaxoSmithKline, Encysive, Lilly and Pfizer. DB has acted as a consultant for Actelion Pharmaceuticals Ltd. UM-L UML is a speaker and advisor for Actelion and Roche, and a speaker for GSK and Pfizer. JEP has consulted for and/or had research grants from Actelion, Bayer, Biogen and Celgene. MCV has consultancy relationships, and has received lecture honoraria and/or research funding from Actelion Pharmaceuticals Ltd, Pfizer, GlaxoSmithKline, Therabel Pharma and United Therapeutics. JRS has received consulting fees from Actelion, Aires, Apricus, Bayer, Boehringer-Ingelheim, Celgene, DART, Eiccose, Eiger, EMD Serono, FibroGen, Gilead, InterMune Novartis, 
Pfizer, Sanofi-Aventis, Sigma Tau and United Therapeutics. MD, HC-B and DMR are full-time employees of Actelion Pharmaceuticals Ltd and have stock/stock options in the company. J-VT-M is an ex-employee of Actelion Pharmaceuticals Ltd and currently an employee of Syntax for Science. WM has acted as a consultant and/ or received honoraria/lecture fees from Actelion Pharmaceuticals Ltd, Bayer, Gilead and United Therapeutics. She has received research funding (to the University of Michigan) from Actelion Pharmaceuticals Ltd, Bayer, Novartis and United Therapeutics. DK is a consultant to Actelion, Bayer, Biogen Idec, BMS, DIGNA, Genentech/ Roche, InterMune, Merck, and Sanofi-Aventis/Genzyme. He is funded by NIH/ NIAMS K24 AR063120-02.

\section{Authors' contributions}

SV, DK, HC-B and MD designed the study. OD, JGC, CPD, EG, DB, UML, JEP, MCV, JRS and WM recruited patients to the DETECT study and collected data. HC-B and J-VT-M conducted the statistical analyses. DR provided epidemiology methods input for DETECT. SV and DK drafted the manuscript, which was critically reviewed, edited and approved for submission by all authors.

\section{Acknowledgements}

Actelion Pharmaceuticals Ltd was responsible for designing the DETECT study protocol, data collection and statistical analysis in collaboration and under the leadership of a company-funded, yet independent, Study Scientific Committee. This study was supported in part by NIH/NHLBI K23 HL119623 01A1 (SV) and NIH/NIAMS K24 AR063120-02 (DK). The authors would like to thank all investigators and patients involved in the DETECT study.

\section{Author details}

'Division of Cardiology, Department of Medicine, University of Michigan, Ann Arbor, MI, USA. '2Division of Rheumatology, University Hospital Zurich, Zurich, Switzerland. ${ }^{3}$ Cardiology Department, Royal Free Hospital, London, UK. ${ }^{4}$ Centre for Rheumatology, Royal Free Hospital, London, UK. ${ }^{5}$ Centre for Pulmonary Hypertension, University Hospital, Heidelberg, Germany. ${ }^{6}$ Department of Internal Medicine II, Division of Cardiology, Medical University of Vienna, Vienna, Austria. ${ }^{7}$ Department of Rheumatology and Clinical Immunology, Justus-Liebig University, Giessen, Germany. ${ }^{8}$ Department of Medicine, Division of Rheumatology, Western University of Canada, London, ON, Canada. ${ }^{9}$ Department of Rheumatology, Radboud University Medical Centre, Nijmegen, The Netherlands. ${ }^{10}$ Scleroderma Research Consultants LLC, Litchfield, CT, USA. ${ }^{11}$ Actelion Pharmaceuticals Ltd, Allschwil, Switzerland. ${ }^{12}$ Division of Rheumatology, Department of Internal Medicine, University of Michigan, Ann Arbor, Michigan, USA. ${ }^{13}$ Division of Rheumatology, Department of Internal Medicine, University of Michigan Scleroderma Program, 300 North Ingalls Street, Suite 7C27, Ann Arbor, MI 48109, USA.

Received: 29 May 2014 Accepted: 12 November 2014 Published online: 10 December 2014

\section{References}

1. Steen VD, Medsger TA: Changes in causes of death in systemic sclerosis, 1972-2002. Ann Rheum Dis 2007, 66:940-944.

2. Tyndall AJ, Bannert B, Vonk M, Airo P, Cozzi F, Carreira PE, Bancel DF, Allanore Y, Muller-Ladner U, Distler O, lannone F, Pellerito R, Pileckyte M, Miniati I, Ananieva L, Gurman AB, Damjanov N, Mueller A, Valentini G, Riemekasten G, Tikly M, Hummers L, Henriques MJ, Caramaschi P, Scheja A, Rozman B, Ton E, Kumánovics G, Coleiro B, Feierl E, et al: Causes and risk factors for death in systemic sclerosis: a study from the EULAR Scleroderma Trials and Research (EUSTAR) database. Ann Rheum Dis 2010, 69:1809-1815.

3. Stupi AM, Steen VD, Owens GR, Barnes EL, Rodnan GP, Medsger TA Jr: Pulmonary hypertension in the CREST syndrome variant of systemic sclerosis. Arthritis Rheum 1986, 29:515-524.

4. Condliffe R, Kiely DG, Peacock AJ, Corris PA, Gibbs JS, Vrapi F, Das C, Elliot CA, Johnson M, DeSoyza J, Torpy C, Goldsmith K, Hodgkins D, Hughes RJ, Pepke-Zaba J, Coghlan JG: Connective tissue disease-associated pulmonary arterial hypertension in the modern treatment era. Am J Respir Crit Care Med 2009, 179:151-157.

5. Kuhn KP, Byrne DW, Arbogast PG, Doyle TP, Loyd JE, Robbins IM: Outcome in 91 consecutive patients with pulmonary arterial hypertension receiving epoprostenol. Am J Respir Crit Care Med 2003, 167:580-586.
6. Clements PJ, Tan M, McLaughlin W, Oudiz RJ, Tapson VF, Channick RN, Rubin $L$, Langer A: The pulmonary arterial hypertension quality enhancement research initiative: comparison of patients with idiopathic $\mathrm{PAH}$ to patients with systemic sclerosis-associated PAH. Ann Rheum Dis 2012, 71:249-252.

7. Rubenfire M, Huffman M, Krishnan S, Seibold JR, Schiopu E, McLaughlin W: Survival in systemic sclerosis with pulmonary arterial hypertension has not improved in the modern era. Chest 2013, 144:1282.

8. Humbert M, Yaici A, de Groote P, Montani D, Sitbon O, Launay D, Gressin V, Guillevin L, Clerson P, Simonneau G, Hachulla E: Screening for pulmonary arterial hypertension in patients with systemic sclerosis: clinical characteristics at diagnosis and long-term survival. Arthritis Rheum 2011, 63:3522-3530.

9. McLaughlin W, Archer SL, Badesch DB, Barst RJ, Farber HW, Lindner JR, Mathier MA, McGoon MD, Park MH, Rosenson RS, Rubin LJ, Tapson VF, Varga J: ACCF/AHA 2009 expert consensus document on pulmonary hypertension a report of the American College of Cardiology Foundation Task Force on Expert Consensus Documents and the American Heart Association developed in collaboration with the American College of Chest Physicians; American Thoracic Society, Inc.; and the Pulmonary Hypertension Association. J Am Coll Cardiol 2009, 53:1573-1619.

10. Khanna D, Gladue H, Channick R, Chung L, Distler O, Furst DE, Hachulla E, Humbert M, Langleben D, Mathai SC, Saggar R, Visovatti S, Altorok N, Townsend W, FitzGerald J, McLaughlin W: Recommendations for screening and detection of connective tissue disease-associated pulmonary arterial hypertension. Arthritis Rheum 2013, 65:3194-3201.

11. Coghlan JG, Denton CP, Grunig E, Bonderman D, Distler O, Khanna D, Muller-Ladner U, Pope JE, Vonk MC, Doelberg M, Chadha-Boreham H, Heinzl $H$, Rosenberg DM, McLaughlin W, Seibold JR: Evidence-based detection of pulmonary arterial hypertension in systemic sclerosis: the DETECT study. Ann Rheum Dis 2013, 73:1340-1349.

12. Kovacs G, Berghold A, Scheidl S, Olschewski H: Pulmonary arterial pressure during rest and exercise in healthy subjects: a systematic review. Eur Respir J 2009, 34:888-894.

13. Hoeper MM, Bogaard HJ, Condliffe R, Frantz R, Khanna D, Kurzyna M, Langleben D, Manes A, Satoh T, Torres F, Wilkins MR, Badesch DB: Definitions and diagnosis of pulmonary hypertension. J Am Coll Cardio/ 2013, 62:D42-D50.

14. Bae S, Saggar R, Bolster MB, Chung L, Csuka ME, Derk C, Domsic R, Fischer A, Frech T, Goldberg A, Hinchcliff M, Hsu V, Hummers L, Schiopu E, Mayes MD, McLaughlin V, Molitor J, Naz N, Furst DE, Maranian P, Steen V, Khanna $D$ : Baseline characteristics and follow-up in patients with normal haemodynamics versus borderline mean pulmonary arterial pressure in systemic sclerosis: results from the PHAROS registry. Ann Rheum Dis 2012, 71:1335-1342

15. Valerio CJ, Schreiber BE, Handler CE, Denton CP, Coghlan JG: Borderline mean pulmonary artery pressure in patients with systemic sclerosis: transpulmonary gradient predicts risk of developing pulmonary hypertension. Arthritis Rheum 2013, 65:1074-1084.

16. Masi AT, Subcommittee for Scleroderma Criteria of the American Rheumatism Association Diagnostic and Therapeutic Criteria Committee: Preliminary criteria for the classification of systemic sclerosis (scleroderma). Subcommittee for scleroderma criteria of the American Rheumatism Association Diagnostic and Therapeutic Criteria Committee. Arthritis Rheum 1980, 23:581-590.

17. Chobanian AV, Bakris GL, Black HR, Cushman WC, Green LA, Izzo JL Jr, Jones DW, Materson BJ, Oparil S, Wright JT Jr, Roccella EJ: The Seventh Report of the Joint National Committee on Prevention, Detection, Evaluation, and Treatment of High Blood Pressure: the JNC 7 report. JAMA 2003, 289:2560-2572.

18. Lang RM, Bierig M, Devereux RB, Flachskampf FA, Foster E, Pellikka PA, Picard MH, Roman MJ, Seward J, Shanewise JS, Solomon SD, Spencer KT, Sutton MS, Stewart WJ: Recommendations for chamber quantification: a report from the American Society of Echocardiography's Guidelines and Standards Committee and the Chamber Quantification Writing Group, developed in conjunction with the European Association of Echocardiography, a branch of the European Society of Cardiology. J Am Soc Echocardiogr 2005, 18:1440-1463.

19. Galie N, Rubin L, Hoeper M, Jansa P, Al-Hiti H, Meyer G, Chiossi E, Kusic-Pajic A, Simonneau G: Treatment of patients with mildly symptomatic pulmonary arterial hypertension with bosentan (EARLY study): a double-blind, randomised controlled trial. Lancet 2008, 371:2093-2100.

20. Kovacs G, Maier R, Aberer E, Brodmann M, Scheidl S, Troster N, Hesse C, Salmhofer W, Graninger W, Gruenig E, Rubin LJ, Olschewski H: Borderline 
pulmonary arterial pressure is associated with decreased exercise capacity in scleroderma. Am J Respir Crit Care Med 2009, 180:881-886.

21. Hinchcliff M, Fischer A, Schiopu E, Steen VD: Pulmonary Hypertension Assessment and Recognition of Outcomes in Scleroderma (PHAROS): baseline characteristics and description of study population. J Rheumatol 2011, 38:2172-2179.

22. Johnson SR, Fransen J, Khanna D, Baron M, van den Hoogen F, Medsger TA Jr, Peschken CA, Carreira PE, Riemekasten G, Tyndall A, Matucci-Cerinic M, Pope JE: Validation of potential classification criteria for systemic sclerosis. Arthritis Care Res (Hoboken) 2012, 64:358-367.

23. Thenappan T, Shah SJ, Rich S, Gomberg-Maitland M: A USA-based registry for pulmonary arterial hypertension: 1982-2006. Eur Respir J 2007, 30:1 103-1110.

24. Gladue H, Steen V, Allanore Y, Saggar R, Saggar R, Maranian P, Berrocal VJ, Avouac J, Meune C, Trivedi M, Khanna D: Combination of echocardiographic and pulmonary function test measures improves sensitivity for diagnosis of systemic sclerosis-associated pulmonary arterial hypertension: analysis of 2 cohorts. J Rheumatol 2013, 40:1706-1711.

25. Njaman W, lesaki T, Iwama Y, Takasaki Y, Daida H: Serum uric Acid as a prognostic predictor in pulmonary arterial hypertension with connective tissue disease. Int Heart J 2007, 48:523-532.

26. Naeije R, Vachiery JL, Yerly P, Vanderpool R: The transpulmonary pressure gradient for the diagnosis of pulmonary vascular disease. Eur Respir $J$ 2013, 41:217-223.

27. Robbins IM, Hemnes AR, Pugh ME, Brittain EL, Zhao DX, Piana RN, Fong PP, Newman JH: High prevalence of occult pulmonary venous hypertension revealed by fluid challenge in pulmonary hypertension. Circ Heart Fail 2014, 7:116-122.

28. Fox BD, Shimony A, Langleben D, Hirsch A, Rudski L, Schlesinger R,

Eisenberg MJ, Joyal D, Hudson M, Boutet K, Serban A, Masetto A, Baron M: High prevalence of occult left heart disease in scleroderma-pulmonary hypertension. Eur Respir J 2013, 42:1083-1091.

\section{Submit your next manuscript to BioMed Central and take full advantage of:}

- Convenient online submission

- Thorough peer review

- No space constraints or color figure charges

- Immediate publication on acceptance

- Inclusion in PubMed, CAS, Scopus and Google Scholar

- Research which is freely available for redistribution 